\title{
A Study of Emergency Communication System of Nuclear Power Plant in Severe Accident Condition
}

\author{
Zhai Shouyang ${ }^{1, a, *}$, Jiang Shangyue ${ }^{1, b}$, Chen Yan $^{1, c}$ \\ ${ }^{1}$ China Nuclear Power Design Company, Ltd(Shenzhen), Shenzhen, Guangdong, China \\ aemail: zhaishouyang@163.com, bemail:jiangshangyue@cgnpc.com.cn, \\ cemail: chen_yan@cgnpc.com.cn \\ *corresponding author
}

Keywords: Nuclear power plant; emergency communication; severe accident.

\begin{abstract}
According to the structure research of emergency communication system of nuclear power plant, this paper proposes a technical scheme of emergency communication system of nuclear power plant to ensure the multiplicity, diversity and redundancy of emergency communication methods. By researching the composition structure of emergency communication system as well as communication support and recovery of minimum safety system in severe accident condition, this paper states the design principles and functional requirements of emergency communication system. It has great guiding significance to the design of emergency communication system of nuclear power plant in severe accident condition. This study can not only apply to second generation nuclear power plant, but also apply to third generation nuclear power plants being built or to be built such as AP1000, HPR1000 and EPR, which has vast potential for future development.
\end{abstract}

\section{Introduction}

In severe accident condition, the release of parameter status and transmission of control command of nuclear power plant rely on the unblocked communication system. Although the emergency communication system is not a nuclear safety related system, the system will play an important supporting role to ensure effective information and command transmission in nuclear emergency situation. The emergency communication system can satisfy the command, management and coordination of in-plant nuclear emergency response ${ }^{[1]}$ and give technical support to keep the communication clear between organizations in plant and out of plant.

This paper aims to study the design principles, functional requirements, composition structure, communication support and recovery of minimum safety communication system in severe accident condition. By effective organization, utilization and management of emergency communication system, it can provide strong support for nuclear emergency response. The whole communication system of nuclear power plant is not designed dedicatedly for emergency response purpose, but part of the system can be utilized immediately or converted into dedicated emergency system when in 
emergency. This can save the investment of nuclear power plant. Meanwhile, based on the real-time monitoring and intelligent management, it can avoid severe consequence causing by the unavailable of communication system which has not detected in time. In this way it can ensure the availability, safety and reliability of emergency communication system. So the communication system can provide safe and effective communication measures for quick nuclear emergency response and correct rescue to ensure the barriers of nuclear safety ${ }^{[2-8]}$..

\section{Design principle}

The emergency communication system should be designed according to the following principles:

- Active compatibility and a few dedicated principles. The whole communication system of nuclear power plant is not designed dedicatedly for emergency response purpose, but part of the system can be utilized immediately or converted into dedicated emergency system when in emergency. A few dedicated communication subsystems that are set for emergency purpose can also be used for non-emergency purpose in normal times. But when needed, they can be used for emergency response whenever necessary.

- In order to ensure the reliability of emergency communication system, the system should have enough redundancy. What is more, it should also satisfy the following requirement such as diversity, anti interference, anti blocking and anti illegal interception of information.

- The setting of emergency communication system should consider the position and function of every emergency response facilities, local natrual terrain obstacles, off-site emergency organization and emergency organization and staffs of the plant operation company.

\section{Design principle}

The emergency communication system of nuclear power plant should have the following functions:

- Ensure the communication contact and data information transmission among emergency facilities and related emergency organizations in nuclear power plant.

- Ensure the communication contact among related emergency organizations in the plant and out of the plant.

- Ensure the data information transmission to national nuclear security regulator and off-site emergency organizations from the plant.

- Rapid response. The system should transmit and receive unit status parameters, environment monitoring and evaluation result, as well as other kinds of information generated during emergency response in real time and accurately.

- System reliability. To ensure the safety and reliability of the emergency communication system through optimization design and periodical maintenance test. At the same time, the communication scheduling scheme is developed to improve the scheduling ability of emergency communication personnel, so as to ensure that the emergency communication is available at any time.

- Multiple protection. The design of emergency communication can meet the requirements of redundancy, diversity and multiple protection, so as to ensure the reliability of emergency communication.

\section{System structure}

The design of emergency communication system is based on the principle of mutual compatibility between the emergency communication and the conventional communication, as well 
as the multiplicity and diversity of communication means, and the requirement of sufficient margin. Function structure of emergency communication system is shown in Figure 1. The system is composed by normal telephone system, safety telephone system, grid telephone system, wireless communication system, sound powered telephone system, public address system, sound alarm system, direct telephone, satellite telephone, and communication equipment monitoring system, etc.

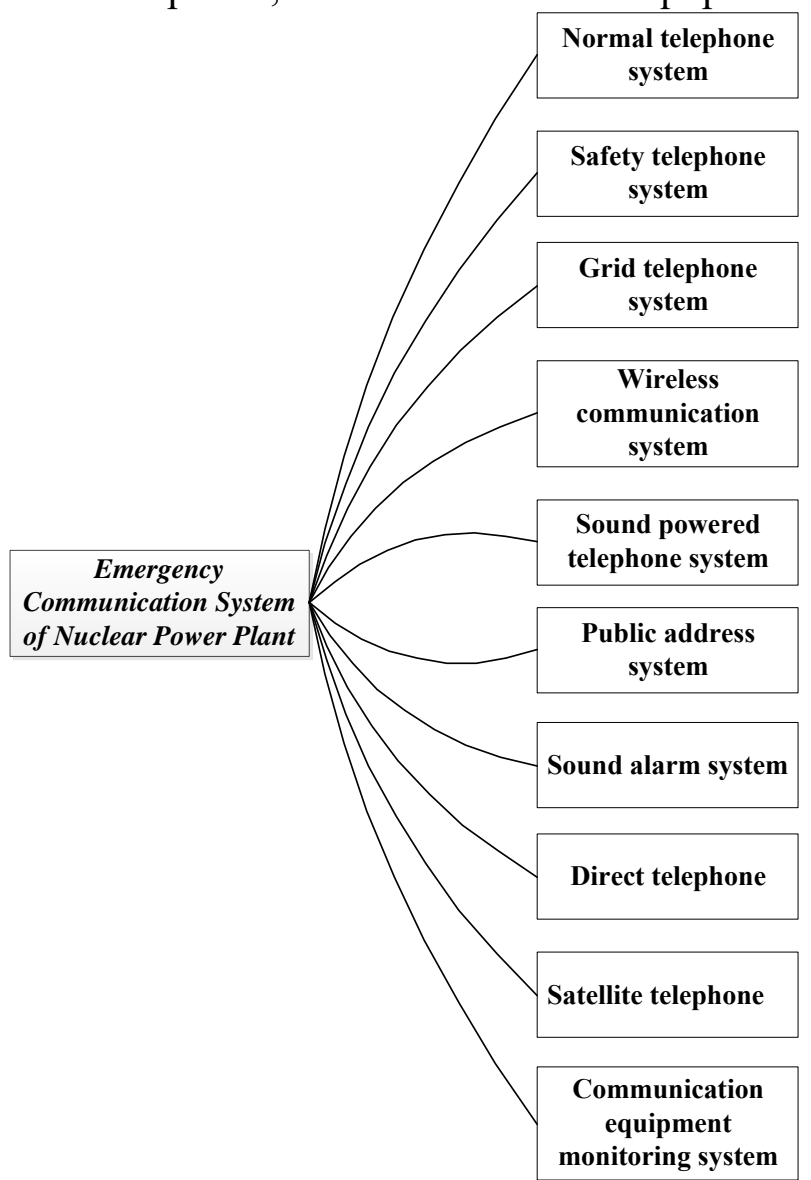

Figure 1 Function structure of emergency communication system.

\subsection{Normal telephone system}

The normal telephone system of nuclear power plant is used to provide telephone service for all the buildings in the nuclear power plant. The main equipment of the system located in the central communication rooms in office building and building in central region of the plant. It consists of a telephone switch, remote telephone module, remote maintenance terminal, etc..

\subsection{Safety telephone system}

Safety telephone system is provided with a safety telephone PABX (SPABX). The system connects every key and important position related to emergency and safety in nuclear power plant, so as to keep communication reliable and effective in the nuclear power plant accident and emergency situations. 


\subsection{Grid telephone system}

The grid telephone system is mainly to realize the communication between the nuclear power plant and the power grid, the provincial electric power dispatching center and the related substations. The telephone switch is installed in $500 \mathrm{kV}$ switch station, which connects to each level electric power dispatching center, substations, control room of $500 \mathrm{kV}$ switch station and users in nuclear power plant. It can provide grid dispatching and grid administration telephone services.

\subsection{Wireless communication system}

The wireless communication system cooperates with wired telephone system. It is used for paging and issuing nuclear emergency information to satisfy the mobile communication needs in normal operation condition and emergency condition. The system is built dedicated for nuclear power plant, and it is different from the wireless public network.

\subsection{Sound powered telephone system}

Sound powered telephone system is used in nuclear power plant for equipment test and maintenance operation. The telephone cables connect with sound powered sockets on site and sound powered switch box in main control room. So operation personnel can talk with each other using sound powered phones or headphones. The system is a passive system which does not need external power supply.

\subsection{Public address system}

Public address system is used for paging and emergency notification from the main control room, remote shutdown station, or emergency command center. It has the function of partition paging and priority paging, and support broadcasting in normal, fire accidents and other accidents conditions. The system is mainly composed of power amplifiers, network controller, power supply device, system management server and software, control panels, and loudspeakers, etc. The loudspeakers are installed all through the nuclear island, conventional island and BOP buildings

\subsection{Sound alarm system}

Public address system is used for issuing sound alarm signals from the main control room, remote shutdown station, or emergency command center in emergency condition. The sirens are installed all through the nuclear island, conventional island and BOP buildings. The plant personnel can take action according to different alarm signal type.

\subsection{Direct telephone}

Direct telephone is a telephone line provided by the telecommunication operator. During the emergency response, it can provide telephone service between the power plant emergency organization and the national and local emergency command authorities and emergency support organizations. 


\subsection{Satellite telephone}

Satellite telephone can be directly linked with the outside world (including the national nuclear accident emergency office, the state environmental protection department emergency center, the provincial nuclear emergency command and other authorities) in the nuclear emergency condition.

\subsection{Communication equipment monitoring system}

Communication equipment monitoring system can monitor the communication room environment, temperature and humidity, air conditioning, and power supply. It can also collect the alarm data of main equipments of the communication system and send data to the control center. Important equipment fault can be timely notified to the operation and maintenance personnel by mobile phone short messages. It is a system to ensure the reliability of the whole emergency communication system.

\section{Organization of emergency communication}

Emergency communication system should be able to ensure the internal communication within the nuclear power plant and external communication with the nuclear safety regulatory authorities, off-site emergency organizations during the emergency response.

\subsection{Internal communication}

During the emergency response, the internal communication of the nuclear power plant mainly refers to the communication between the emergency facilities. The main emergency facilities include the main control room, remote shutdown station, emergency control center, technical support center, etc.. The following is an analysis of the emergency communication system of emergency facilities. The organization diagram of the internal communication within the nuclear power plant is shown in figure 2 . 


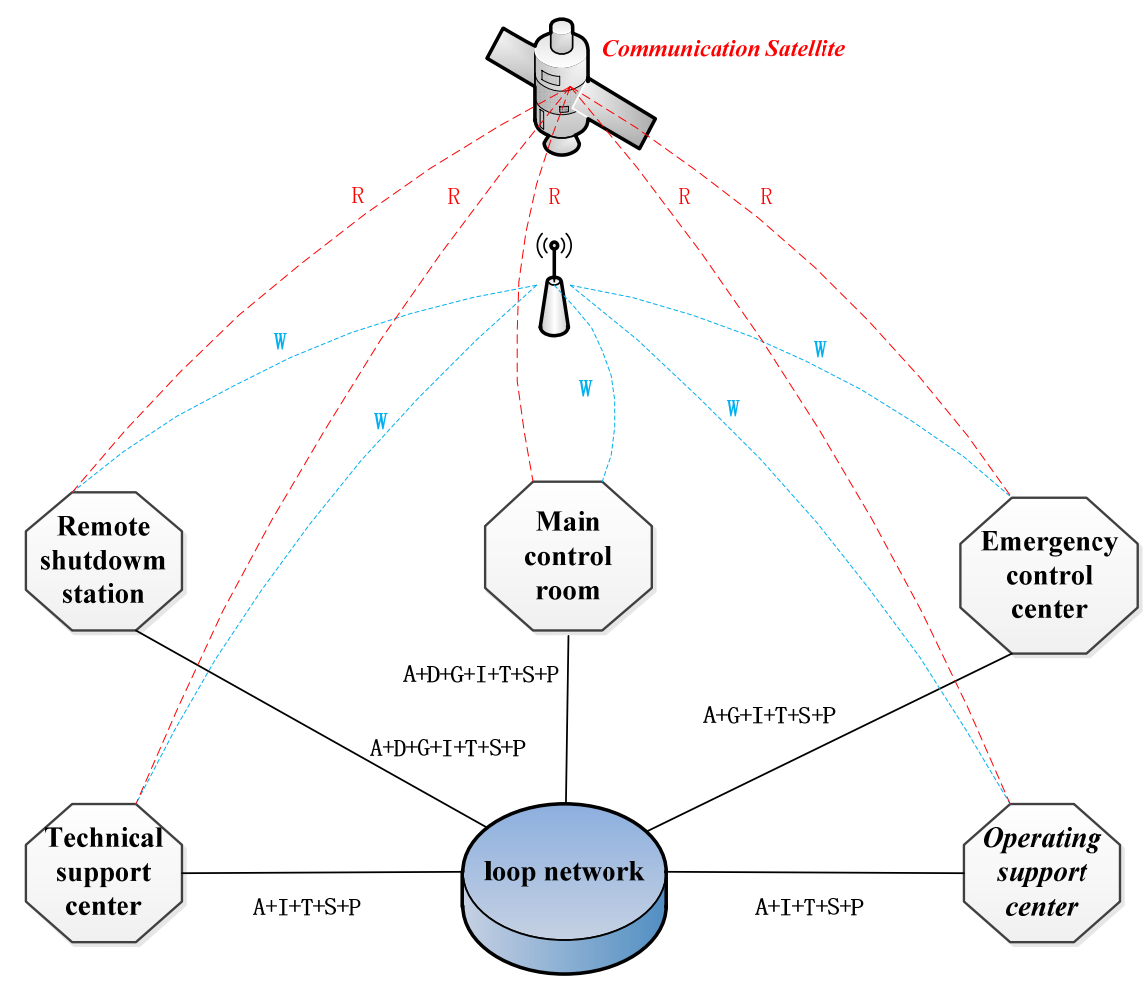

Figure 2 The organization diagram of the internal communication within the nuclear power plant.

( NOTE:A:Sound alarm system; D:Grid telephone system; G:Sound powered telephone system; I: Direct telephone; P:Public address system; R:Satellite telephone; S:Safety telephone system; T:Normal telephone system; W:Wireless communication system.)

\subsubsection{Main control room}

Emergency communication system in the main control room sets up several means of communication include normal telephone, safety telephone, public address, sound alarm, wireless communication, direct telephone, satellite telephone. There are four telephone dispatching panels in main control room. These four panels are connected together through the plant integrated transmission system. Any one telephone panel can dial or receive normal and safety telephone. The public address control panel can broadcast emergency notification to the whole plant or certain partition of the plant. The sound alarm control panel can trigger different kinds of emergency alarms to the whole plant or certain partition of the plant. The wireless communication control panel can send emergency short messages containing important notifications to the personnel of the whole plant or certain user group. The direct telephone and satellite telephone act as a backup method in case of communicate system failure of normal telephone and safety telephone.

\subsubsection{Remote shutdowm station}

Emergency communication system in the remote shutdown station sets up several means of communication include normal telephone, safety telephone, public address, sound alarm, wireless communication, direct telephone, satellite telephone. The emergency communication system in remote shutdown station is a backup system for the system in main control room. The equipments are installed on communication panel in remote shutdown station. The functions of telephone control panel, public address control panel and sound alarm control panel are the same as the panels in main control room. When main control room retreat to remote shutdown station, the 
communication panels can also switch to remote shutdown station. The emergency short message function is integrated into telephone control panel in order to save the space of communication panel. The direct telephone and satellite telephone also act as a backup method to communicate in case of system failure of normal telephone and safety telephone.

\subsubsection{Emergency control center}

Emergency control center is located in the building of emergency command center. Emergency communication system in emergency control center include normal telephone, safety telephone, public address, sound alarm, wireless communication, direct telephone, satellite telephone. The function of these systems are the same as those in main control room. When in emergency, the emergency control center acts as the top priority status in the whole plant, so do the emergency communication equipments inside.

\subsubsection{Technical support center}

There is no communication control panel in technical support center. But it has communication terminals including normal telephone, safety telephone, loudspeaker, siren and direct telephone to ensure the communication.

\subsection{External communication}

External communication mainly refers to the communication between the nuclear power plant and nuclear safety regulatory authority, as well as the off-site emergency response organizations. The organization diagram of the external communication is shown in figure 3 .

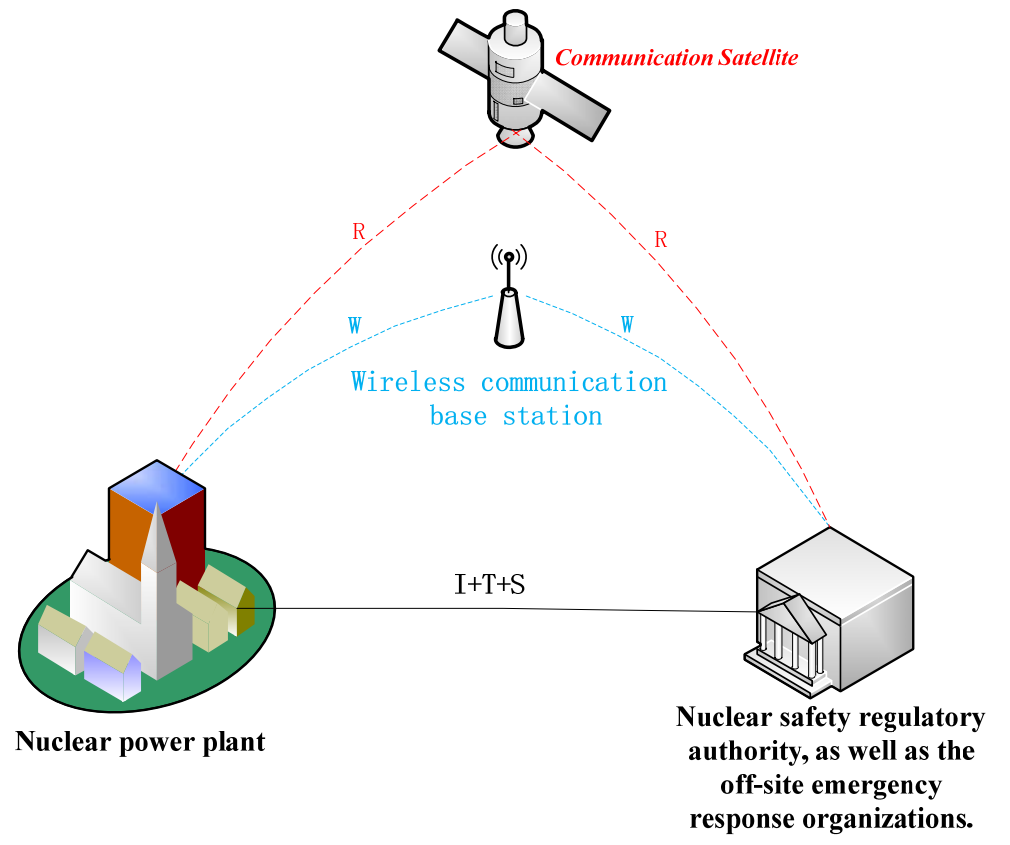

Figure 3 The organization diagram of the external communication

( NOTE: I: Direct telephone; R:Satellite telephone; S:Safety telephone system; T:Normal telephone system; W:Wireless communication system.) 


\subsubsection{Normal telephone}

The main switch of the normal telephone system is connected with the outside public telephone network. During the emergency response, it can use telephone dispatching panel and telephone terminals to communicate with outside world.

\subsubsection{Safety telephone}

The main switch of the normal telephone system is connected with the outside public telephone network, and the relay connection is different from normal telephone system to enhance reliability. During the emergency response, it can use telephone dispatching panel and telephone terminals to communicate with outside world.

\subsubsection{Direct telephone}

Direct telephone service is provide by public telecom operator. The telephone signal does not need to go through telephone switch of normal or safety telephone. During the emergency response, even the telephone switches in plant are in failure, direct telephone can still contact with outside world if the link of public telecom operator is still working.

\subsubsection{Satellite telephone}

Satellite telephone service does not rely on public telecom operator or the switch of normal or safety telephone. During the emergency response, even the telephone switches in plant and the link of public telecom operator are in failure, satellite telephone can still contact with outside world.

\section{Communication support of minimum safety system}

The communication system in nuclear power plant is much more sophisticate than the system in other industrial fields. It has several special systems that other industrial fields do not have, such as safety telephone system and sound powered telephone system. In the condition of nuclear accident, the subsystems of emergency communication system can work coordinately to ensure the communication during nuclear accident. For voice communication, the normal telephone system can be used. But normal telephone can only be used inside the plant because the relay to the outside world is cut down. If the staffs want to make voice communication with outside world, safety telephone system can be used. And safety telephone system can play a backup role when normal telephone system is down. Even both normal and safety telephone system are down because of lack of power supply, staffs can still use sound powered telephone system as it is a passive system which do not need external power supply. Satellite telephone is the last method to communicated with each other since it is an independent system which does not need to connect with other system and has a backup power supply itself. For emergency information notification, public address system and sound alarm system act as a backup system to each other since both the systems can broadcast alarm notification.

In the condition of nuclear accident, there is a so called "minimum safety system". If the equipments of minimum safety system operate normally, the reactor can be safely shutdown. Necessary communication ways can support the operation personnel when they are dealing with the emergency. Telephones are set in the rooms where minimum safety system equipments located, so as to ensure the communication with main control room, remote shutdown station and emergency control center, etc. Meanwhile, the signal coverage of public address, sound alarm and wireless communication in the rooms where minimum safety system equipments located should be good so 
as to guarantee the transmission of notification. The diagram of communication support of minimum safety system is shown in figure 4.

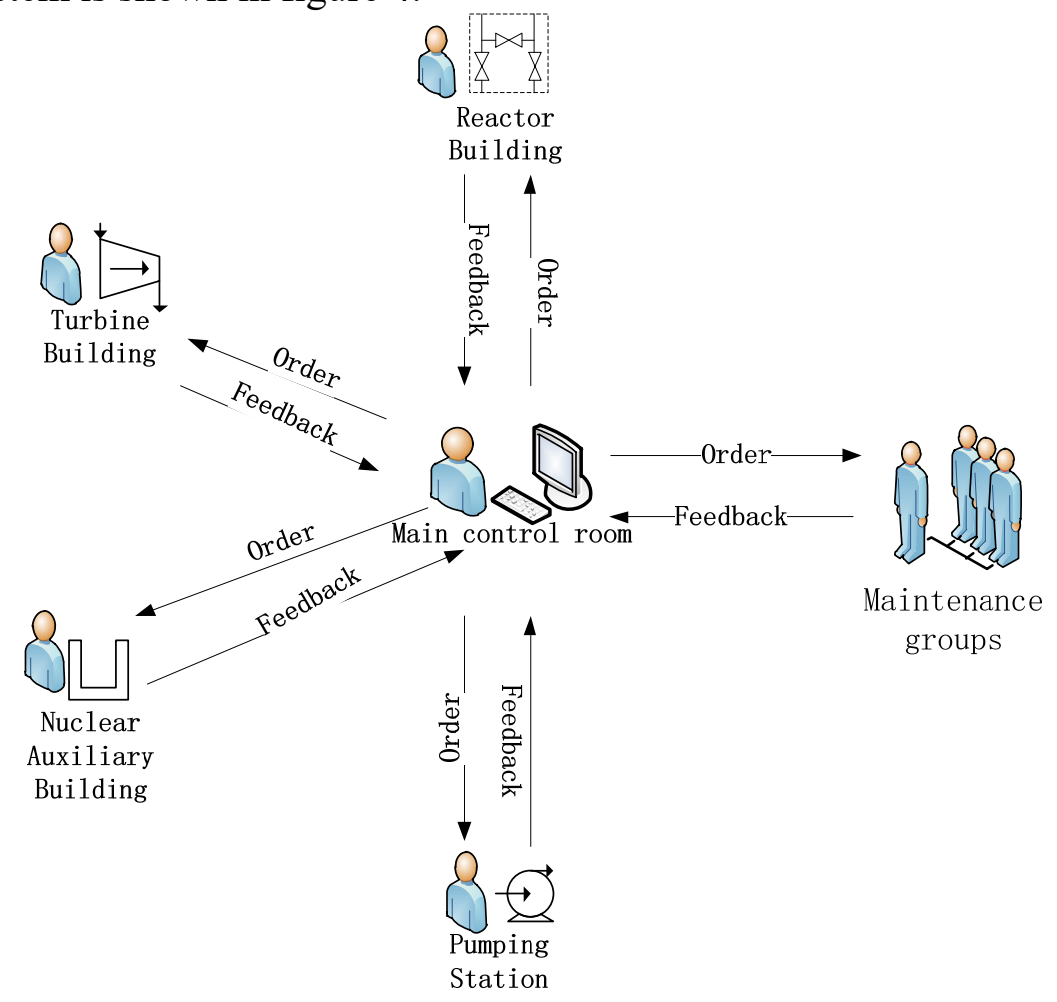

Figure 4 The diagram of communication support of minimum safety system

\section{Communication recovery in severe accident}

The main steps of communication recovery in severe accident condition is shown below.

Step 1: Confirm the position of failure communication equipment and failure reason.

Step 2: Evaluate the possibility of maintenance and recovery of failure communication equipment, including maintenance necessity, maintenance personnel ready or not, the path is available or not (road damage, radiation contamination), maintenance tool ready or not, maintenance time enough or not, etc.

Step 3: Send maintenance personnel to repair.

Step 4: If maintenance is not necessary, change backup communication equipment directly.

\section{Conclusion}

This paper puts forward the design scheme of the emergency communication system of nuclear power plant through the research of structure and design of nuclear power plant emergency communication system to ensure the multiplicity, diversity and sufficient margin of the system. The study has great guiding significance to the design of emergency communication system of nuclear power plant in severe accident condition. This study can not only apply to second generation nuclear power plant, but also apply to third generation nuclear power plants being built or to be built such as AP1000, HPR1000 and EPR, which has vast potential for future development. 


\section{References}

[1] Jiang Shangyue, Cao Yu, Zhai Shouyang, Deng Xiaofei, “Technical Plan for Improving Reliability of Main Control Room Communicaion System in Nuclear Power Plants” , Nuclear Power Engineering, Vol.30,No.6(S2), pp. 35-38, 2009

[2] Jiang Shangyue, Chai Baofa, Cao Yu, Zhai Shouyang, Deng Xiaofei,. "Study of the technical solution to the dedicated wireless communication system in nuclear power plant” . Nuclear Science and Engineering,. Vol.30 (S1), pp.275 279, 2010

[3] Chen Long, LIU Yuming, Chen Wen,"Research on Coverage of TD-LTE in Electric Power Emergency Communication". Yunnan Electric Power.Vol.44(5),pp.69 71,2016

[4] Wang Hai-tao,Song Li-hua, Huang Zhao-cui, Wang Chen-yu , "Conceive of Construction of Integrative Emergency Communication System”.Communication Countermeasures. Vol.35(2),pp.1 4,8,2016

[5] Zhu You-min,Zheng Lin,Liu Wei,"Status Quo and Forecast for Integrated Aerospace Emergency Communication System".Mobile Communications. Vol.40(11),pp.45 50,2016

[6] Jia Xiaofang "Application of short wave communication in electric power emergency communication”.ElectronicTest.No.6,pp.149,155,2016

[7] PawelczaPP.,etal. Cognitive radio emergency networks - re- quirements and design.in New Frontiers in Dynamic Spectrum Access Networks, 2005. DySPAN 2005. 2005 First IEEE Interna- tional Symposium on.2005

[8] CHITI F, FANTACCI R. Abroadband wireless communica- tions system for emergency mnagement [J]. IEEE Wireless Communications, 2008, 7(6): 8-14. 